\title{
Covid-19 Pandemic and Possible Links with Mthfr Mutations, Homocysteinemia, and Metabolic Disturbances: Short Review
}

\author{
Journal of Diabetes and Endocrinology Research
}

Short Review

Raul H. Morales-Borges ${ }^{* *}$ and Michael J. Gonzalez ${ }^{2}$

\author{
${ }^{I}$ Medical Director, Integrative Optimal Health of Puerto Rico, \\ San Juan PR \\ ${ }^{2}$ Professor of School of Public Health, Department of Human \\ Development, University of Puerto Rico, San Juan, PR
}

\author{
"Correspondence author \\ Raul H. Morales-Borges \\ Medical Director \\ Integrative Optimal Health of Puerto Rico. 29 Washington \\ St. Suite \# 107 \\ San Juan PR 0907-1509
}

Submitted : 22 Sept 2020 ; Published : 7 Oct 2020

\begin{abstract}
Coronovirus-19 (COVID-19) is an associate degree infection caused by the SARS-CoV-2 virus inflicting a worldwide pandemic and chiefly characterized by respiratory symptoms, many times accompanied by a cytokine storm. It causes migration of the neutrophils, macrophages and inflammatory cytokines resulting in the destruction of the alveolarcapillary walls. Coagulopathy in patients with COVID-19 may be a common complication that jeopardizes the clinical course and is related to poorer outcomes and probable death. The methylenetetrahydrofolate enzyme (MTHFR) is coded by the gene with the image MTHFR on chromosome one location p36.3 in humans, and there are desoxyribonucleic acid sequence variants (genetic polymorphisms) related to this gene. However, the 2 commonest ones are C677T and A1298C. Deficiencies within the production of this accelerator are related to raise risk of cardiac muscle infarctions, stroke, thrombosis, and several conditions. Homocysteine (Hcy) is a chemical in the blood formed when the amino acid methionine, a building block of the proteins, is naturally metabolized to be excreted in the urine; throughout this breakdown method, our body will recycle homocysteine to be reused to make different proteins. For this utilization, we need vitamins B12, B6, and folate. Also, for utilization to be the foremost economical, the accelerator MTHFR is needed. Transmissible mutations within the factor that create the MTHFR accelerator will result in an associate degree accelerator that's not optimally active and should result in elevated homocysteine levels. Several medical conditions, like vascular disorders, obesity, diabetic disorder, peripheral neuropathy, and thrombophilia's inside others, are associated with high Hcy levels and MTHFR mutations. Few reports link the high risk and poor prognosis with COVID-19 with MTHFR mutation and metabolic disorders like obesity and Diabetes mellitus. In this this review, we provide recommendations to prevent complications in patients with COVID, MTHFR mutations, Diabetes, and Obesity.
\end{abstract}

Keywords: COVID-19, MTHFR mutation, Homocysteinemia, Metabolic Disturbances

\section{Introduction}

SARS-CoV2 is a member of the beta Coronavirus family. It's a positive-sense, single-stranded RNA, enveloped virus that is $50-200 \mathrm{~nm}$ in diameter [1]. On the thirty first of October of 2019, the city health commission of the Republic of China notified the National Health Commission, China CDC, and WHO of a cluster of twenty seven cases of respiratory disorder of unknown etiology [2]. On the seventh of January 2020, the China Center for Disease Control and Prevention discovered the virus referred to as novel coronavirus 2019 (2019-nCoV), conjointly named because the "Wuhan Coronavirus." The WHO renamed it to SARS-CoV-2 to destigmatize the virus's association with any geographic location or position and relate it to the unwellness symptomatology. This case eventually precipitated into the WHO declaring this pneumonia as a scourge on thirtieth of January 2020. By March 2020, the coronavirus 2019 (COVID-19) was declared an endemic by the WHO because of the worldwide power growth [3]. Of crucial importance are medical specialty investigations to characterize transmission modes, copy interval, and clinical spectrum ensuing from infection to tell and refine ways which will control and stop the unfold of 2019-nCoV [4].

The interaction between the viral spike (S) supermolecule and angiotensin-converting accelerator that triggers the virus's entry into host cells, is probably going to be a concerned within the vascular manifestations of COVID-19. The presence of 
underlying vascular comorbidities in patients with COVID-19 is related to high mortality. COVID-19 will cause vascular disorders, together with heart muscle injury, arrhythmias, acute coronary syndrome, and blood vessel occlusion [5]. This virus could dispose patients to thrombotic unwellness, each within the blood vessel and blood vessel circulations, due to excessive inflammation, protoplasm activation, epithelium dysfunction, and stasis [6]. Besides, several patients receiving medication medical care for the thrombotic unwellness could still develop on COVID-19 patients, which might have implications for selection, dosing, and laboratory watching of antithrombotic medical care. COVID-19 patients with pre-existing vascular conditions are typically at a far higher risk of exaggerated morbidity and mortality [7].

Hyperhomocysteinemia (H-Hcy) activates a pro-inflammatory cascade through the upregulation of the nuclear transcription issue (NF-kB) in neutrophils and macrophages that unharness associate degree ample quantity of ROS potentiating aerobic oxidative stress. This acute H-Hcy can be triggered independently of folate status when a systemic inflammatory process rapidly develops [8]. The increased production of ROS through an acute respiratory viral infection additionally overwhelms the oxidant defense system. The ROS-activated NF-kB accelerates viral replication, previously shown in SARS CoV-1 disease [9]. Interestingly, in line with these findings, COVID-19 patients' plasma homocysteine levels showed a predictive value for the pathological conclusions' progression in chest CT-imaging [10].

In distinction to the same old definition of H-Hcy with values higher than fifteen $\mu \mathrm{mol} / \mathrm{L}$, the cutoff-value of Hcy predicting imaging progression was $10.58 \mu \mathrm{mol} / \mathrm{L}$ [10]. In a remarkable case report, glutathione's therapeutic supplementation ends up in speedy symptom improvement of 2 cases of Covid-19, all of that purpose to the outstanding role of glutathione as a vital a part of the anti-oxidative defense system in microorganism ill health [11]. Karst et al. projected a theory of specific vulnerability to a severe course of COVID-19 initiated by $\mathrm{H}-\mathrm{Hcy}$, which might be triggered by the presence of the C677T polymorphism [12]. Male gender, nutritional factors, lifestyle factors, and several other underlying diseases appear to be additional vital risk factors for exaggerated vulnerability to SARS-CoV-2. Throughout the SARS-CoV-2 pandemic, early risk stratification by measuring of Hcy-plasma levels and presumably screening for the presence of MTHFR polymorphism seems promising [12].

\section{COVID-19, MTHFR, H-Hcy, Diabetes \& Obesity: Controversies \& Management}

The severity of COVID-19 disease intensifies in patients with elevated glucose levels, probably via amplified proinflammatory cytokine response, low innate immunity, and downregulated angiotensin-converting enzyme 2 (ACE-2). Thus, using ACE inhibitors or angiotensin receptor blockers may want to get worse the glucose degree in sufferers stricken by novel coronavirus infection. It also observed that the direct $\beta$-cell damage caused by virus, hypokalemia, and cytokine and
fetuin-A mediated increase in insulin resistance could even deteriorate the diabetic condition in COVID-19.

An essential feature of COVID-19 pandemics is the high incidence of fatalities in elderly patients: this might be due to the prevalence of fragility and cardiovascular disease increase with age due to endothelial disruption and loss of endogenous cardioprotective mechanisms [13]. Experimental evidence on this topic is still early. Still, Moccia et al. hypothesized and discussed more suggestive cellular and molecular mechanisms whereby SARS-CoV-2 may lead to detrimental consequences to the cardiovascular system. They focused on aging, cytokine storm, NLRP3/inflammasome, hypoxemia, and air pollution, an emerging cardiovascular risk factor associated with rapid urbanization and globalization [14].

Obesity, Diabetes (DM), and MTHFR polymorphisms are linked together and carry a high risk for society globally and higher costs in healthcare. From a disease management and prevention perspective, many studies have demonstrated that genetic screening for the polymorphisms, serum folate, and Hcy levels and aggressive nutritional evaluation and management should be applied to decrease the morbidity and mortality with these combinations [15]. Now with the COVID-19 pandemic, we should be more aggressive.

Glucose and glutamine are good sources of energy for viruses [16]. A high glucose condition affects immune function, and conversely, impairs the regulated immune status and finally causes macrovascular complications [17,18]. A high blood glucose level in people with DM may provide a favorable environment for increasing [19]. Also, infection with SARS CoV-1 causes hyperglycemia without preexisting DM [20]. It is possible that DM, when not well controlled, may increase the risk of complications arising from COVID-19 and death [19].

COVID-19 affects the immune system, and these links may also worsen the complications of obesity. Of note, excess production of interleukin 6 (IL-6) and other cytokines released in response to COVID-19 can induce a "cytokine storm" (hypercytokinemia), which is believed to increase the fatality of COVID-19. COVID-19 can also progress to severe respiratory illness and hypoxia, which may predispose people to be immobile and gaining weight [19]. A cumulative effect of chronic inflammation and hypercytokinemia seems to bring about a hyperinflammatory response through active macrophage syndrome, especially in severe COVID-19. This event subsequently leads to hypoxia and ischemia, which results in an oxidative stress state involving the release of inflammatory proteins and reactive oxygen species that impair mitochondrial function. As a result, protein synthesis by hypertrophic and hypoxic white adipocytes is altered toward the production of cytokines and other inflammatory proteins, which may lead to metabolic disease [21,22]. Hyperglycemia or type $2 \mathrm{DM}$ is commonly associated with obese patients; it was reported in $51 \%$ of patients with SARS-CoV-2 infection and has been suggested as an independent predictor of poor 
prognosis in patients SARS-CoV-2 [23,24].

Regarding the management of these cases, the patients should be followed closely in respect of their hematologic and metabolic parameters. Glucagon-like peptide-1 (GLP1) analogs have an anti-inflammatory effect, reduces monocyte infiltration and improves reendothelialization, increasing nitric oxide production in endothelial cells; therefore, alleviation of inflammatory processes in the vascular system by these agents is a rationale for the recommendation to prescribe GLP1 analogs during the COVID- 19 pandemic [25-27]. Dipeptidyl peptidase-4 (DPP4) inhibitors are one of the most frequently prescribed medications for patients with DM and play an important role in various biological processes, such as proliferation, T-cell immunity, and glucose homeostasis, but at present, there is insufficient evidence either for or against the use of DPP4 inhibitors in patients with DM and COVID-19 $[19,28,29]$.

ACE-2 and potential therapeutic implications have been mentioned above. ACE-2 expression may be implicated in the severe illness caused by COVID-19. Higher expression of ACE-2 in patients with hypertension and cardiovascular disease has been postulated as a factor that increases the susceptibility to SARS-CoV-2 [30]. A recent study of 417 COVID-19 patients showed that ACE inhibitors or angiotensin receptor blocker therapy was associated with a decreased rate of severe disease, less systemic inflammation, and lower peak viral load compared with the use of other antihypertensive drugs [31]. Experts strongly recommend that patients should not stop taking their renin-angiotensin-aldosterone system (RAAS) inhibitor during the COVID-19 pandemic [32].

Hydroxymethylglutaryl-CoA reductase inhibitors or statins have anti-inflammatory properties. In a viral pneumonia mouse model, simvastatin directly modulated antiviral inflammatory responses in lung tissues attenuating airway inflammation, such as RANTES (regulated on activation, normal T-cell expressed and secreted) expression neutrophil recruitments [33]. Rosuvastatin therapy also has additional benefits, including anti-inflammatory effects beyond the lipid-lowering property, suggesting that this drug has pleiotropic effects [34]. These data support the favorable effects of statins on respiratory diseases [35]. Statin therapy should be continued during the COVID-19 pandemic if there is no definite contraindication.

Concerning MTHFR mutation and COVID-19 patients together, the risk of hypertension and cardiovascular events is higher. So, riboflavin, combined with folic acid, may be an important modulator in those adults, and treatment with vitamins and micronutrients and standard supportive care seems to be warranted to protect and support the most vulnerable patient group $[12,36]$.

Aspirin has been shown for years to be the cost-effective antiplatelet aggregation therapy in cardiovascular disease. In a meta-analysis of ischemic cardiopathy using (i) 75 studies during which the prevalence of a mutation (CT) in the MTHFR gene (which increases homocysteine)determined in cases
$(22,068)$ and controls $(23,618)$, and (ii) 14 randomized trials (39,597 participants) of homocysteine-lowering and ischemic heart condition events. A meta-analysis of the MTHFR studies showed a statistically significantly increased risk of ischemic cardiovascular disease in TT compared with CC homozygotes. A meta-analysis of randomized trials showed no significant reduction in IHD risk from folic acid, despite reducing homocysteine of $3.3 \mu \mathrm{mol} / \mathrm{L}$. There was a major difference in risk reduction between the five trials with the lowest prevalence of antiplatelet therapy (60\% on the average, usual aspirin), RR 0.93 ( 0.84 to 1.05$)$, and therefore the five trials with the best prevalence (91\% on average), RR 1.09 (1.00 to 1.19), p $=0.037$ for the difference [37]. A secondary analysis of a $10-$ year randomized, double-blind, placebo-controlled trial with 39876 initially healthy women age 45 years or older (26 779 evaluated for clotting factor Leiden, G20210A prothrombin, and MTHFR $677 \mathrm{C}>\mathrm{T}$ polymorphisms) suggested that longterm, low-dose aspirin treatment has little effect on the prevention of deep vein thrombosis and embolism in initially healthy women [38].

Human physiology depends on countless biochemical reactions, many of which are co-dependent and interrelated. The rapidness and completeness of reactions usually rely on the supply of precursors and enzymes. The enzymatic activity depends on the bioavailability of micronutrients, like vitamins and minerals. To realize a healthy state, the organism requires that biochemical reactions occur at a controlled rate. It required that metabolic reactions reach what can be considered an optimal metabolic equilibrium. A mixture of genetic makeup, dietary patterns, trauma, disease, toxins, medications, and environmental stressors can elevate the demand for the nutrients needed to achieve this optimal metabolic equilibrium [39]. We don't have to just treat deficiencies, so it's important to stay up our metabolism. The authors explained it fine. Metabolic correction improves enzymatic function and satisfies the increasing demand for nutrients. Metabolic correction can significantly impact the reduction of morbidity and mortality and their financial cost to our society and contribute to improving health and well-being [40].

Vitamin $\mathrm{C}$ is an important nutrient for humans, with pleiotropic functions associated with its ability to donate electrons. Vitamin $\mathrm{C}$ contributes to immune defense by supporting and directly stimulating various cellular processes of both the innate and adaptive immune systems. Consistent with this documented ability of vitamin $\mathrm{C}$ to modulate the immune system, scientific literature has abundant documentation of vitamin C's ability to cure several viruses' infections [39]. The authors reported a case where the viral infection had reached the point of being life-threatening, while it absolutely was afflicting a young man who previously had always been in exemplary physiologically state [41]. They treated him with Intravenous Vitamin C (IVC) therapy 50 grams for three infusions over three days. They determined that ascorbic acid possesses anti-viral activity, which confirmed with other cases reported in cold rhinovirus, avian virus H1N1, Chikungunya, Zika, and influenza [42-47]. Miranda-Massari et al. did a superb recent review about the 
role of vitamin C in COVID-19, and that they mentioned the Shanghai Expert Consensus on COVID-19 Treatment and therefore the International Pulmonologist Consensus Group recommendations on IVC in COVID-19 infections [48].

\section{Conclusions}

In general, because of the high prevalence of obesity, DM, and MTHFR mutations and the COVID-19 pandemic in this new era, we recommend close observations on them and be more aggressive in their management. A combination of low carb diet, weight management, GLP1 analogs, ACE-2 inhibitors, low-dose aspirin, Magnesium, Zinc, vitamin C, and B-complex plus folate supplementation, preferably the activated form, 5 methyl folate for all cases with those comorbidities. Intravenous Vitamin C is recommended for patients that got admitted.

\section{References}

1. Xu X, Chen P, Wang J, Feng J, Zhou H, Li X, Zhong W, Hao P (2020) Evolution of the novel coronavirus from the ongoing Wuhan outbreak and modeling of its spike protein for risk of human transmission. Science China Life Sciences 63(3): 457-460.

2. Lu H, Stratton CW, Tang YW (2020) Outbreak of pneumonia of unknown etiology in Wuhan, China: The mystery and the miracle. J Med Virol 92(4): 401-402. doi:10.1002/jmv.25678

3. Kakodkar P, Kaka N, Baig MN (2020) A comprehensive literature review on the clinical presentation, and management of the pandemic coronavirus disease 2019 (COVID-19). Cureus. 2020 Apr;12(4). doi: 10.7759/ cureus. 7560

4. Zhu N, Zhang D, Wang W, et al. (2020) A novel coronavirus from patients with pneumonia in China, 2019. N.Engl.J.Med 382(8): 727-733. doi: 10.1056/ NEJMoa2001017

5. Nishiga M, Wang DW, Han Y, Lewis DB, Wu JC (2020) COVID-19 and cardiovascular disease: from basic mechanisms to clinical perspectives. Nat Rev Cardiol 17(9): 543-558. doi: 10.1038/s41569-020-0413-9.

6. Bikdeli B, Madhavan MV, Jimenez D, Chuich T, Dreyfus I, Driggin E, Der Nigoghossian C, Ageno W, Madjid M, Guo Y, Tang LV (2020) COVID-19 and Thrombotic or Thromboembolic Disease: Implications for Prevention, Antithrombotic Therapy, and Follow-Up: JACC Stateof-the-Art Review. Journal of the American College of Cardiology 75(23): 2950-2973. doi: 10.1016/j. jacc.2020.04.031

7. Wu L, O'Kane AM, Peng H, Bi Y, Motriuk-Smith D, Ren J (2020) SARS-CoV-2 and cardiovascular complications: From molecular mechanisms to pharmaceutical management. Biochem Pharmacol 178: 114114. doi: 10.1016/j.bcp.2020.114114.

8. Moretti R (2019) Homocysteine: New Aspects of an Ancient Enigma. Cardiology 144(1-2): 36-39.

9. Smits SL, De Lang A, Van Den Brand JM, Leijten LM, Van Ijcken WF, Eijkemans MJ, Van Amerongen G,
Kuiken T, Andeweg AC, Osterhaus AD, Haagmans BL (2010) Exacerbated innate host response to SARS-CoV in aged non-human primates. PLoS Pathog 6(2): e1000756.

10. Yang Z, Shi J, He Z, Lü Y, Xu Q, Ye C, Chen S, Tang B, Yin K, Lu Y, Chen X (2020) Predictors for imaging progression on chest CT from coronavirus disease 2019 (COVID-19) patients. Aging (Albany NY) 12(7): 6037.

11. Horowitz RI, Freeman PR, Bruzzese J (2020) Efficacy of glutathione therapy in relieving dyspnea associated with COVID-19 pneumonia: A report of 2 cases. Respiratory medicine case reports. 2020 Apr 21:101063.

12. Karst M, Hollenhorst J, Achenbach J (2020) Lifethreatening Course in Coronavirus Disease 2019 (COVID-19): Is There a Link to Methylenetetrahydrofolic Acid Reductase (MTHFR) Polymorphism and Hyperhomocysteinemia?. Medical Hypotheses 144: 110234. https://doi.org/10.1016/j.mehy.2020.110234

13. Das S, K R A, Birangal SR, Nikam AN, Pandey A, Mutalik S, Joseph A (2020) Role of comorbidities like diabetes on severe acute respiratory syndrome coronavirus-2: A review. Life Sci. 258: 118202. doi: 10.1016/j.lfs.2020.118202.

14. Moccia F, Gerbino A, Lionetti V, Miragoli M, Munaron LM, Pagliaro P, Pasqua T, Penna C, Rocca C, Samaja M, Angelone T (2020) COVID-19-associated cardiovascular morbidity in older adults: a position paper from the Italian Society of Cardiovascular Researches. Geroscience 42(4): 1021-1049. doi: 10.1007/s11357-020-00198-w.

15. Morales-Borges RH (2019) Obesity, Diabetes mellitus, and Methylenetetrahydrofolate reductase mutations: Deadly combinations? How to approach them?. Journal of Diabetes and Endocrinology Research 1(1): 1-4.

16. Thai M, Thaker SK, Feng J, Du Y, Hu H, Ting Wu T, et al. (2015) MYC-induced reprogramming of glutamine catabolism supports optimal virus replication. Nat Commun 6: 8873. doi: 10.1038/ncomms9873.

17. Mehta P, McAuley DF, Brown M, Sanchez E, Tattersall RS, Manson JJ, et al. (2020) COVID-19: consider cytokine storm syndromes and immunosuppression. Lancet 395: 1033-1034. doi: 10.1016/S0140-6736(20)30628-0.

18. Zhang Y, Xiao M, Zhang S, Xia P, Cao W, Jiang W, et al. (2020) Coagulopathy and antiphospholipid antibodies in patients with Covid-19. $N$ Engl J Med 382: e38. doi: 10.1056/NEJMc2007575.

19. Lim S, Shin SM, Nam GE, Jung CH, Koo BK (2020) Proper Management of People with Obesity during the COVID-19 Pandemic. J Obes Metab Syndr 29(2): 84-98. doi:10.7570/jomes20056.

20. Yang JK, Lin SS, Ji XJ, Guo LM (2010) Binding of SARS coronavirus to its receptor damages islets and causes acute diabetes. Acta Diabetol 47: 193-199. doi: 10.1007/ s00592-009-0109-4.

21. Ellulu MS, Patimah I, Khaza'ai H, Rahmat A, Abed Y (2017) Obesity and inflammation: the linking mechanism and the complications. Arch Med Sci 13: 851-863. doi: 10.5114/aoms.2016.58928.

22. Stone TW, McPherson M, Gail Darlington L (2018) Obesity and cancer: existing and new hypotheses for a causal connection. E Bio Medicine 30: 14-28. doi: 10.1016/j.ebiom.2018.02.022. 
23. Chen N, Zhou M, Dong X, Qu J, Gong F, Han Y, et al. (2020) Epidemiological and clinical characteristics of 99 cases of 2019 novel coronavirus pneumonia in Wuhan, China: a descriptive study. Lancet 395: 507-513. doi: 10.1016/S0140-6736(20)30211-7.

24. Ilias I, Zabuliene L (2020) Hyperglycemia and the novel Covid-19 infection: possible pathophysiologic mechanisms. Med Hypotheses 139: 109699. doi: 10.1016/j.mehy.2020.109699.

25. Lim S, Lee GY, Park HS, Lee DH, Tae Jung O, Kyoung Min K, et al (2017) Attenuation of carotid neointimal formation after direct delivery of a recombinant adenovirus expressing glucagon-like peptide-1 in diabetic rats. Cardiovasc Res 113: 183-194. doi: 10.1093/cvr/cvw213.

26. Noyan-Ashraf MH, Shikatani EA, Schuiki I, Mukovozov I, Wu J, Li RK, et al. (2013) A glucagon-like peptide-1 analog reverses the molecular pathology and cardiac dysfunction of a mouse model of obesity. Circulation 127: 74-85. doi: 10.1161/CIRCULATIONAHA.112.091215

27. Shiraishi D, Fujiwara Y, Komohara Y, Mizuta H, Takeya M (2012) Glucagon-like peptide-1 (GLP-1) induces M2 polarization of human macrophages via STAT3 activation. Biochem Biophys Res Commun 425: 304-308. doi: 10.1016/j.bbrc.2012.07.086.

28. Mentlein R (1999) Dipeptidyl-peptidase IV (CD26): role in the inactivation of regulatory peptides. Regul Pept 85: 9-24. doi: 10.1016/S0167-0115(99)00089-0.

29. Iacobellis G (2020) COVID-19 and diabetes: can DPP4 inhibition play a role? Diabetes Res Clin Pract 162: 108125. doi: 10.1016/j.diabres.2020.108125.

30. South AM, Diz DI, Chappell MC (2020) COVID-19, ACE2, and the cardiovascular consequences. Am J Physiol Heart Circ Physiol 318(5): H1084-H1090. doi:10.1152/ ajpheart.00217.2020.

31. Meng J, Xiao G, Zhang J, He X, Ou M, Bi J, et al. (2020) Renin-angiotensin system inhibitors improve the clinical outcomes of COVID-19 patients with hypertension. Emerg Microbes Infect 9: 757-760. doi: 10.1080/22221751.2020.1746200.

32. Danser AH, Epstein M, Batlle D (2020) Renin-angiotensin system blockers and the COVID-19 pandemic: at present there is no evidence to abandon renin-angiotensin system blockers. Hypertension 75: 1382-1385. doi: 10.1161/ HYPERTENSIONAHA.120.15082.

33. Lee CS, Yi EH, Lee JK, Won C, Lee YJ, Shin MK, et al. (2013) Simvastatin suppresses RANTES-mediated neutrophilia in polyinosinic-polycytidylic acidinduced pneumonia. Eur Respir J 41: 1147-1156. doi: 10.1183/09031936.00050612.

34. Oesterle A, Laufs U, Liao JK (2017) Pleiotropic effects of statins on the cardiovascular system. Circ Res 120: 229243. doi: 10.1161/CIRCRESAHA.116.308537.

35. Frost FJ, Petersen H, Tollestrup K, Skipper B (2007) Influenza and COPD mortality protection as pleiotropic, dose-dependent effects of statins. Chest 131: 1006-1012. doi: 10.1378/chest.06-1997.

36. Rooney M (2020) The interaction of B-vitamins with MTHFR genotype concerning blood pressure and vascular health. 2020. Doctoral dissertation, Ulster University.
37. Wald DS, Morris JK, Wald NJ (2011) Reconciling the evidence on serum homocysteine and ischaemic heart disease: a meta-analysis. PloS one 6(2): e16473.

38. Glynn RJ, Ridker PM, Goldhaber SZ, Buring JE (2007) Effect of low-dose aspirin on the occurrence of venous thromboembolism: a randomized trial. Annals of internal medicine 147(8): 525-533.

39. Gonzalez MJ, Miranda-Massari JR, Duconge J, AllendeVigo MZ, Jiménez-Ramírez FJ, Cintrón K, RodríguezGómez JR, Rosario G, Ricart C, Santiago-Cornier JA, Zaragoza-Urdaz R (2015) Metabolic Correction: A Functional Biochemical Mechanism against Disease Part 1: Concept and Historical Background. Puerto Rico Health Science Journal 34(1): 3-8.

40. Miranda-Massari JR, González MJ, Duconge J, AllendeVigo MZ, Jiménez-Ramírez FJ, Hickey S, Vázquez A, Berdiel MJ, Cintrón K, Rodríguez-Gómez JR (2015) Metabolic Correction: A Functional Biochemical Mechanism against Disease Part 2: Mechanisms and Benefits. Puerto Rico Health Science Journal 34(1): 9-13.

41. Gonzalez MJ, Berdiel MJ, Duconge J, Levy TE, Alfaro IM, Morales-Borges R, Marcial-Vega V, Olalde J (2018) High dose vitamin $\mathrm{C}$ and influenza: a case report. $J$. Orthomol. Med 33(3).

42. Hemilä H and Herman ZS (1995) Vitamin C and the common cold: A retrospective analysis of Chalmers' review. J Am Coll Nutr 14(2): 116-123.

43. Ely JT (2007) Ascorbic acid role in containment of the world avian flu pandemic. Exp Biol Med 232(7): 847-851.

44. Gonzalez MJ, Miranda-Massari JR, Berdiel MJ, Duconge J, Rodríguez-López JL, Hunninghake R, Cobas-Rosario VJ (2014) High dose intraveneous vitamin $\mathrm{C}$ and chikungunya fever: A case report. $J$ Orthomolec Med 29(4): 154-156.

45. Marcial-Vega V, Gonzalez- Terron I, LevyTE (2015) Intravenous ascorbic acid and hydrogen peroxide in the management of patients with chikungunya. Bol Asoc Med Puert Rico 107(1): 20-24.

46. Gonzalez MJ, Berdiel MJ, Miranda-Massari JR, Duconge J, Rodríguez-López JL, Adrover-López PA (2016) High dose intravenous vitamin $\mathrm{C}$ treatment for zika fever. $J$ Orthomolec Med 31(1): 19-22.

47. Zarubaeva VV, Slitaa AV, Lavrentyevaa IN, Smirnovb VS (2017) Protective activity of ascorbic acid at influenza infection. Russian J Infection and Immunity 7(4): 319-326.

48. Miranda-Massari JR, González MJ, Marcial-Vega VA, Soler JD (2020) A Possible Role for Ascorbic Acid in COVID-19. Journal of Restorative Medicine 10(1).

Copyright: (C2020 Raul H. Morales-Borges. This is an open-access article distributed under the terms of the Creative Commons Attribution License, which permits unrestricted use, distribution, and reproduction in any medium, provided the original author and source are credited. 